\title{
Pobreza e tomada de decisão financeira: evidências de uma pesquisa em assentamentos rurais no estado de Tocantins
}

\author{
Poverty and financial decision-making: evidence from a survey of \\ rural settlements in the state of Tocantins \\ Fernando Sérgio de Toledo Fonseca ${ }^{1}$ (1) \\ 1Universidade Federal do Tocantins (UFT), Palmas (TO), Brasil. E-mail: fernandofonseca@uft.edu.br
}

\begin{abstract}
Como citar: Fonseca, F. S. T. (2022). Pobreza e tomada de decisão financeira: evidências de uma pesquisa em assentamentos rurais no estado de Tocantins. Revista de Economia e Sociologia Rural, 60(spe), e245649. https://doi. org/10.1590/1806-9479.2021.245649
\end{abstract}

\begin{abstract}
Resumo: Uma vasta literatura recente na área de economia comportamental tem investigado como a pobreza afeta a tomada de decisão financeira, considerando vieses cognitivos no processo decisório individual. No Brasil, há pouquíssimos trabalhos empíricos que abordam a influência de vieses cognitivos na tomada de decisão das famílias pobres. O objetivo deste trabalho é avaliar empiricamente como as famílias pobres tomam decisões em relação à poupança. Foi realizada uma pesquisa de campo a partir de uma amostra intencional não probabilística em assentamentos rurais no norte do estado de Tocantins. Como estratégia para coleta de dados, foram realizadas entrevistas semiestruturadas com responsáveis da unidade familiar. Conclui-se que a baixa capacidade de aspiração e o viés do presente, potencializados pela condição de pobreza, comprometem severamente a capacidade de poupança e a tomada de decisão em relação ao futuro dessas famílias. As escolhas feitas perpetuam sua condição de pobreza. Desse modo, algumas lições e sugestões são extraídas do estudo para o aprofundamento de pesquisas futuras e o aprimoramento do desenho de políticas.
\end{abstract}

Palavras-chave: escolha intertemporal, poupança, pobreza rural.

\begin{abstract}
A vast recent literature in the area of behavioral economics has investigated how poverty affects financial decision-making, considering cognitive biases in the individual decision-making process. In Brazil, there are very few empirical studies that address the influence of cognitive biases on poor families' decisionmaking. This paper aims to empirically assess how poor families make savings decisions. Field research carried out from an intentional non-probabilistic sample in rural settlements in the northern state of Tocantins. As a strategy for data collection, semi-structured interviews were conducted with heads of the family unit. It is concluded that the low capacity to aspire and the present bias, enhanced by the condition of poverty, severely compromise the ability to save and make decisions regarding the future of these families. Their choices perpetuate their condition of poverty. In this way, some lessons and suggestions are extracted from the study to deepen future research and improve policy design.
\end{abstract}

Keywords: intertemporal choice, savings, rural poverty.

\section{Introdução}

A pobreza não está relacionada apenas a um déficit de recursos materiais ou escassez de renda, mas também ao contexto em que as decisões são tomadas, o que pode impor uma sobrecarga cognitiva aos indivíduos, tornando a tomada de decisão econômica mais complexa. Os pobres precisam demandar uma grande quantidade de energia mental todos os dias para garantir o acesso aos produtos de primeira necessidade, como alimentos e água potável, diferentemente dos não pobres, que vivem em locais de boa infraestrutura (Mullainathan \& Shafir, 2013; World Bank Group, 2015). 
No contexto do desenvolvimento, uma vasta literatura recente tem definido as vantagens de usar os insights da economia comportamental na luta contra a pobreza. Essa nova abordagem estuda o comportamento dos pobres e a implementação de políticas públicas, reconhecendo a ineficácia de muitos programas sociais terem relação com os frágeis fundamentos psicológicos da teoria econômica tradicional (Bertrand et al., 2004; Banerjee \& Duflo, 2012).

Um sinal claro dos avanços na área é a atribuição de prêmios Nobel de Economia aos pesquisadores que militam em economia comportamental e experimental. Mais recentemente, em 2019, o prêmio foi entregue a Esther Duflo e Abhijit Banerjee, do Instituto de Tecnologia de Massachusetts (MIT), e Michael Kremer, da Universidade de Harvard, justificado pelo uso e difusão de experimentos randomizados controlados como ferramentas metodológicas úteis para a coleta de dados empíricos e o desenho de políticas de combate à pobreza.

Ao contrário do que as teorias econômicas e financeiras tradicionais apregoam e o senso comum imagina, as populações pobres desenvolvem, ainda que muitas vezes circunscritas ao manejo de pequenos negócios, assíduas e criativas fórmulas de trocas econômicas. Embora a maioria dos atos financeiros dos pobres se processe em mercados imperfeitos, essa crescente literatura tem apresentado que os pobres querem e podem poupar (Morduch \& Schneider, 2017; Collins et al., 2009; Abramovay, 2004).

O trabalho de Stuart Rutherford (1999) mostra que os pobres querem e podem poupar e, quando não poupam, não é por falta de capacidade, mas sim de oportunidade. Segundo o autor, os pobres poupam sob a forma de pequenos volumes de recursos monetários. As famílias de baixa renda demandam recursos a todo tempo para atender às suas necessidades mais elementares e fazem um esforço contínuo para guardar dinheiro. Mas, afinal, se os pobres têm vida financeira e querem poupar, como sugere parte dessa literatura, por que não poupam?

Duas hipóteses norteiam este trabalho. A primeira sugere que o baixo uso do serviço de poupança formal (bancária) das famílias pobres pode estar relacionado aos elevados custos de transação para realizar depósitos em um banco comercial. A segunda hipótese está associada ao viés do presente, potencializado pela condição de pobreza, ou seja, dado seu baixo nível de aspirações, os pobres tendem a priorizar resultados de curto prazo. Isso pode comprometer a realização de poupança e, consequentemente, os investimentos em seu futuro.

Portanto, o objetivo desta pesquisa é avaliar empiricamente como as famílias que vivem em condição de pobreza tomam decisões em relação à poupança na perspectiva da economia comportamental. Mais especificamente, busca-se estudar a tomada de decisão financeira e a vida econômica das famílias pobres de assentamentos rurais na região norte do estado de Tocantins.

A escolha da referida região como lócus da pesquisa de campo se justifica pela alta incidência de pobreza. O território coberto pela pesquisa faz parte da Amazônia Legal e é caracterizado como região de fronteira agrícola, com constantes conflitos agrários e grandes desigualdades sociais. No Brasil, há pouquíssimos trabalhos empíricos que abordam a influência de vieses cognitivos, em especial o viés do presente na tomada de decisão das famílias de baixa renda em relação à poupança.

Além desta introdução, o trabalho é composto por outras quatro seções. A segunda seção apresenta uma revisão da literatura sobre as teorias da pobreza na perspectiva da economia comportamental. Os aspectos metodológicos da pesquisa de campo são apresentados na terceira seção. Os resultados e a discussão da pesquisa são expostos na quarta seção. Por fim, a quinta seção resume as descobertas da pesquisa de campo e reflete suas implicações para futuros trabalhos. 


\section{Fundamentação teórica}

A pesquisa comportamental aplicada vem ganhando força com o crescente reconhecimento da necessidade de novos referenciais teóricos e procedimentos metodológicos para resolver questões complexas relacionadas ao desenvolvimento e ao combate à pobreza. A visão clássica, segundo a qual a pobreza consiste na privação material ou na falta de renda, é apenas uma das dimensões da pobreza. Amartya Sen (2010), economista-filósofo ganhador do Prêmio Nobel, argumenta há alguns anos que a pobreza consiste na privação de algumas capacidades (capabilities) ${ }^{1}$ básicas exigidas minimamente das pessoas. O que as pessoas realmente são capazes de fazer e ser? Quais oportunidades reais estão disponíveis para elas?

As contribuições originadas da abordagem das capacidades de Sen (2010) caracterizam a pobreza como a ausência de liberdade, bem como a discussão da deficiência de capacidades relacionadas à dificuldade de exercer escolhas. Essa perspectiva abre espaço para a análise do fenômeno da pobreza nas dimensões institucionais, sociológicas e, sobretudo, motivacionais e cognitivas.

Por esse ângulo, alguns pesquisadores que investigam dimensões motivacionais e cognitivas na tomada de decisão econômica no contexto da escassez têm encontrado evidências de que o baixo nível de aspirações contribui para a perpetuação da pobreza em comunidades carentes, uma vez que, comparativamente às outras classes sociais, os pobres têm mais dificuldades de enxergar seus próprios talentos, visualizar oportunidades potenciais e estabelecer metas para o futuro (Appadurai, 2004; Alsop et al., 2006; Nussbaum, 2011; Galab et al., 2013; Flechtner, 2016).

De forma complementar à perspectiva da relação entre a pobreza e a falta de aspirações, uma literatura recente na fronteira entre a economia e a psicologia tem investigado as relações entre pobreza, afetos negativos ${ }^{2}$ e tomada de decisão econômica. Atualmente, alguns levantamentos domiciliares já incluem medidas que podem ajudar na avaliação do bem-estar psicológico dos respondentes. Essas pesquisas buscam avaliar se os indivíduos apresentam sintomas de estresse ou depressão (World Bank Group, 2015; World Health Organization, 2019).

Um estudo sobre transtornos mentais da Organização Mundial da Saúde (World Health Organization, 2019) estimou que mais de 300 milhões de pessoas em todo o mundo são afetadas pela depressão. Alguns estudos empíricos sugerem que os pobres são potencialmente suscetíveis a apresentar problemas de depressão, transtornos de ansiedade e estresse pelas adversidades que enfrentam. Nesses estudos, a renda e as condições socioeconômicas dos indivíduos têm correlações conhecidas com o estresse e a ansiedade (Chen et al., 2010; Lupien et al., 2001), com os níveis do hormônio do estresse (Cohen et al., 2001; Li et al., 2007; Haushofer \& Shapiro, 2013) e com a depressão (Dean et al., 2017; Quidt \& Haushofer, 2016; Case \& Deaton, 2009).

Por outro lado, alguns grupos de estudos na área da pesquisa comportamental têm identificado que o problema da escassez é fundamental para entender as nuances comportamentais no âmbito da tomada de decisão econômica das pessoas que vivem em condição de pobreza. Para Mullainathan \& Shafir (2013), a avaliação é que os pobres podem tomar decisões críticas com seus recursos cognitivos e autocontrole exauridos. Consequentemente, esses indivíduos têm maiores chances de cometer erros e tomar decisões de baixa qualidade.

\footnotetext{
1 "Capability" é o termo empregado por Sen que deriva da fusão de "capacity" (capacidade) e "hability" (habilidade). Por causa da dificuldade de tradução da palavra "capability" para o português, optou-se pela utilização do termo "capacidade", que melhor expressa a ideia de oportunidades reais e liberdades substantivas. "Capacidade" denota a pura potência, no sentido aristotélico, do indivíduo de se alterar, transformar e conquistar alguma coisa, seja um estado ou uma atividade.

2 O termo "afeto negativo" também é utilizado na literatura pertinente ao assunto para expressar transtornos mentais relacionados à depressão, ansiedade, tristeza, falta de aspirações e estresse. Ver: Haushofer \& Fehr (2015, p. 140-155).
} 
Os pobres estão expostos a maior restrição orçamentária, o que aumenta a necessidade de ponderar custos de oportunidade, sobrecarregando os seus recursos cognitivos (Shah et al., 2012). Segundo Mullainathan \& Shafir (2013), a largura da banda mental (mental bandwidth) acaba sendo consumida em tarefas relativamente simples. Desse modo, os indivíduos devem gastar uma grande quantidade de energia mental todos os dias para apenas assegurar o acesso às necessidades básicas, tais como obter alimentos e água potável, tendo menos energia para tomar decisões "corretas" do que aqueles que vivem em locais de boa infraestrutura e boas instituições.

Neste cenário, a sobrecarga cognitiva (cognitive burdens) dificulta o pensamento deliberativo dos indivíduos, fazendo com que simplifiquem os problemas e avaliem o mundo por meio de "molduras estreitas" (narrow frames) a partir do seu sistema de crenças. Portanto, a probabilidade de erros é potencializada pela sobrecarga cognitiva imposta pela situação de escassez (Kahneman, 2012; DellaVigna, 2009).

Em especial, as preocupações financeiras urgentes associadas à pobreza modificam a forma como as pessoas alocam sua atenção: as pessoas geram um foco intenso nos problemas do presente, negligenciando os outros do futuro. Por exemplo, a falta de renda em uma família pobre incentiva os pais a retirar as suas crianças da escola para trabalhar, gerando consequências negativas na vida delas no futuro.

Outros estudos na área da pesquisa comportamental avançaram na análise de mecanismos que associam os problemas de autocontrole com a força de vontade limitada (limited willpower) no processo decisório individual. A depleção do ego (ego-depletion), termo utilizado originalmente por Roy Baumeister et al. (1998), por exemplo, sugere que o autocontrole é produzido com um estoque de força de vontade limitada, que, por sua vez, é utilizado temporariamente quando as pessoas regulam suas emoções ou resistem à tentação.

Embora as teses da depleção do ego e da força de vontade limitada não tivessem sido originalmente concebidas para caracterizar a psicologia da pobreza, segundo Dean Spears (2011) a necessidade de autocontrole pode surgir de forma mais intensa, especialmente para os mais pobres. Esse efeito é reforçado pelo fato de muitos dos bens que os pobres desejarão no futuro, como um carro, uma casa própria ou admissão do seu filho em uma faculdade, serem relativamente dispendiosos.

Como resultado, quando essas pessoas têm alguma disponibilidade de dinheiro, os bens tentadores poderão se impor no processo de escolha, adiando, assim, a realização de poupança que fariam para adquirir determinado bem. O resultado é um círculo vicioso: "[...] poupar é menos atraente para os pobres, pois para eles o objetivo tende a estar muito longe e sabem que haverá muitas tentações ao longo do caminho" (Banerjee \& Duflo, 2012, p. 259).

Outras pesquisas detalham casos em que os pobres não conseguem tirar proveito de pequenas oportunidades de investimento de alto retorno por conta do autocontrole, ou seja, os pobres são mais propensos a tomar empréstimos rotineiramente a altas taxas de juros e se endividarem (Aleem, 1990; Banerjee \& Mullainathan, 2010; Ashraf et al., 2006; Karlan et al., 2013).

Neste mesmo campo de pesquisa, economistas comportamentais têm estudado a relação entre escassez e escolha intertemporal no processo decisório individual. De acordo com Frederick et al. (2004), o termo "desconto hiperbólico" é frequentemente usado para indicar que uma pessoa tem uma taxa de desconto declinante ao longo do tempo. Várias pesquisas envolvendo escolha intertemporal têm apresentado evidências de descontos hiperbólicos, ou seja, esses estudos têm constatado que, quando os indivíduos são convidados a comparar uma gratificação monetária menor e imediata com uma gratificação monetária maior e posterior, verifica-se que a taxa de desconto implícita em horizontes de tempo mais longos é menor que 
a taxa de desconto implícita em horizontes de tempo mais curtos (Strotz 1956; Phelps \& Pollak, 1968; Loewenstein \& Prelec, 1992; Laibson, 1977).

Na literatura econômica recente, adotou-se a expressão "viés do presente" para descrever esse tipo de preferência com função de desconto quase hiperbólica. A partir desse conceito, os economistas comportamentais medem o excesso de peso dado ao presente pelas pessoas - o imediatismo -, buscando entender as razões da resistência das pessoas em abrir mão do consumo presente em troca de poupar e elevar seus recursos no futuro (Thaler, 2015; Bianchi, 2018).

Os efeitos deletérios do viés do presente no contexto da pobreza implicam erros sistemáticos na tomada de decisão. Alguns trabalhos sugerem que os indivíduos impacientes são menos propensos a cuidar da saúde, fazer exercícios físicos e manter alimentação saudável, por exemplo (Lehto et al., 2013, Evans et al., 2012). Em condição de pobreza, maior é a dificuldade de as pessoas romperem com os vícios do álcool, tabaco entre outras drogas, tornando-se mais suscetíveis a desenvolver doenças mentais (Peretti-Watel et al., 2013).

No contexto da tomada de decisão econômica, os pobres têm maiores chances de cometer erros e tomar decisões de baixa qualidade. A capacidade de poupar, por exemplo, depende de cálculos intertemporais relativamente complexos e de autocontrole. Segundo Mullainathan \& Shafir (2013), previsivelmente os pobres não apenas teriam menor capacidade de poupança, mas também dificuldade de computar os possíveis ganhos de longo prazo para a poupança e em conter impulsos para o consumo imediato, nas raras circunstâncias de sobra de recursos financeiros.

Para entender os fatores que limitam a tomada de decisão em relação à poupança no contexto da pobreza, Dupas \& Robinson (2013) realizaram experimentos de campo em áreas rurais do Quênia. O estudo teve como base um sistema de poupança comunitária - Associações de Poupança e Crédito Rotativo (ROSCA - Rotating Saving and Credit Associations) - com tecnologias de poupança informal (não bancária). Como resultado geral, verificou-se que a oferta de poupança informal aumentou substancialmente o investimento em saúde preventiva, ajudando a reduzir a vulnerabilidade aos choques de saúde nas comunidades pobres pesquisadas. O fornecimento de um lugar seguro para guardar o dinheiro e mecanismos de compromisso eram suficientes para aumentar a poupança destinada à saúde por meio do efeito de contabilidade mental.

Outros estudos relacionaram mais diretamente as variações da taxa de desconto com os diferentes perfis de comportamento de poupança, endividamento, fatores econômicos e demográficos, permitindo identificar o viés do presente e a baixa tendência à poupança (Meier \& Sprenger, 2009; Wang et al., 2016). Por exemplo, um levantamento realizado pelo Instituto de Pesquisas Datafolha (2017) para medir o grau do imediatismo ou viés do presente identificou que a "paciência" do brasileiro é de 0,26 , número que mostra "imediatismo exacerbado", segundo a pesquisa ${ }^{3}$.

O levantamento mostra ainda que $65 \%$ não poupam para o futuro, revelando imediatismo forte em todas as classes da população, mas maior entre os menos escolarizados e mais pobres. Uma das explicações para a potencialização do viés do presente na pobreza está relacionada à "psicologia da pobreza", conforme alguns estudos aqui apresentados, ou seja, a preocupação com a sobrevivência diária captura a atenção, a memória e o controle da impulsividade, fazendo o indivíduo enfocar no curto prazo e cometer erros que perpetuam sua pobreza (Haushofer \& Fehr, 2015).

3 Segundo a mesma fonte, com base em uma amostra de 45 países, os maiores níveis de paciência foram encontrados nos Estados Unidos (0,77), nos países anglo-saxões $(0,76)$ e no Japão $(0,70)$. O menor resultado foi o da Rússia $(0,21)$. 
Antes de passar à análise de resultados, é necessário descrever brevemente a região pesquisada e os procedimentos metodológicos que guiaram o levantamento de campo e a seleção das famílias entrevistadas, conforme será apresentado na próxima seção.

\section{Metodologia}

Esta seção descreve os procedimentos metodológicos utilizados na pesquisa. São apresentadas as características do norte tocantinense do ponto de vista histórico, os procedimentos para coleta de dados na pesquisa de campo e a metodologia para mensuração da taxa de desconto.

\subsection{Caracterização do norte de Tocantins}

O extremo norte de Goiás ${ }^{4}$, atual norte tocantinense, ficou até meados de 1950 isolado dos grandes centros urbanos, o que contribuiu para a consolidação e o predomínio da agricultura de subsistência em toda a região. De acordo com Maria Cavalcante (1999), essa região era formada por extensas faixas de pastagens naturais com reduzido nível de ocupação, tornando-se forte atrativo aos criadores de gado e pequenos agricultores do Maranhão e Piauí que migraram ao longo do século XIX.

A situação de isolamento regional só começou a mudar com o projeto "Marcha para o Oeste", implantado pelo governo de Getúlio Vargas a partir da década de 1930. Seu objetivo era incorporar as terras do planalto central e povoar a região, permitindo sua expansão econômica por meio da consolidação de um mercado produtor de alimentos.

O resultado dessa política foi a crescente implementação de estradas e rodovias na região e o avanço gradativo da fronteira agrícola. Com a política de colonização do projeto "Marcha para - Oeste", a integração do meio-norte goiano ganhou força. Segundo Binka Breton (2002), para ocupar o território, o governo oferecia terra e emprego para trabalhadores de diversas regiões do país, sobretudo para agricultores pobres do semiárido nordestino que migraram para a Amazônia. Assim, o governo garantia uma reserva de mão de obra barata para a construção de estradas, barragens e cidades para a nova fronteira agrícola.

De acordo com Gerson Oliveira (2010), a ocupação de terras nessa região se deu no bojo do projeto desenvolvimentista estabelecido na política de colonização das chamadas terras devolutas nas décadas de 1940 e 1950. Com a abertura da rodovia Belém-Brasília durante a presidência de Juscelino Kubistchek, as terras valorizavam-se e passaram a ser objeto de especulação no extremo goiano. Para expulsar os posseiros que já estavam na região, as estratégias de grilagens de terras associavam-se a atos de violência: "casas e pertences eram incendiados, lavradores eram ameaçados, quando não efetivamente capturados e mortos" (Carneiro \& Cioccari, 2010, pp. 223-224).

A partir de 1960, surgiram programas especiais, sobretudo políticas de incentivos fiscais, voltados para o desenvolvimento da Amazônia, difundidos também em 60 municípios do norte goiano, atual estado de Tocantins. Os programas de incentivos fiscais e instituições mais representativos que alcançaram essa região foram: Superintendência do Desenvolvimento da Amazônia (SUDAM) (1960), o Polamazônia (1970) e o Projeto Carajás (1980).

A partir dessas políticas e instituições, deu-se a aceleração do processo de integração de toda a Amazônia Legal para incentivar o desenvolvimento da região. Nesta perspectiva, a

${ }^{4}$ Para fins de esclarecimento, os termos "norte de Goiás" ou "meio norte goiano" são utilizados na literatura para se referir ao atual estado de Tocantins. Por outro lado, a expressão "extremo norte goiano" é empregada para se referir ao norte do Tocantins, região objeto de estudo desta pesquisa. 
questão fundiária ganhou importância em todo o país, inclusive no extremo norte goiano e em toda a região amazônica, onde a questão da ocupação de terra se tornou um problema de segurança nacional. Havia o temor dos militares da aproximação dos trabalhadores rurais da região com os movimentos de esquerda armada de outras partes do país (Oliveira, 2010).

Mesmo com as transformações resultantes da incorporação do norte goiano à Amazônia Legal, a região se manteve atrasada em termos econômicos comparativamente ao centro-sul do estado de Goiás. Os grupos que reivindicaram a separação do norte do estado de Goiás caminharam sem uma definição de uma pauta política homogênea até meados da década de 1960. A partir de 1970, lideranças políticas passaram a demandar a criação de um novo estado. Depois de várias tentativas, finalmente foi promulgada na nova constituição brasileira, em 1988, a criação do estado de Tocantins (Oliveira, 2012).

Contudo, apesar dos avanços nos indicadores sociais após a separação do estado de Goiás, - Tocantins continua sendo uma região caracterizada pela extrema pobreza, com grandes desigualdades sociais e intensos conflitos agrários, sobretudo no norte do estado. De acordo com a Síntese dos Indicadores Sociais do Instituto Brasileiro de Geografia e Estatística (2019), o Tocantins conta com 102 mil pessoas vivendo abaixo da linha da extrema pobreza e 486 mil abaixo da linha da pobreza diante de uma população estimada em pouco mais de 1,5 mi de habitantes.

Cerca de 31,5\% da população tocantinense aufere até US $\$ 5,5$ dólares/dia, o que configura um percentual elevado de pobreza na região. Em 2019, o rendimento nominal mensal domiciliar per capita no Tocantins foi de $\mathrm{R} \$ 1.056,00$. A evolução da desigualdade de renda pode ser descrita com a queda pouco expressiva do Índice de Gini, que passou de 0,60, em 2010, para 0,528, em 2019. Cerca de $47,5 \%$ da população economicamente ativa tem carteira de trabalho assinada, o que retrata o baixo grau de formalização do pessoal ocupado, reflexo do reduzido dinamismo econômico dos municípios tocantinenses na geração de emprego e renda (Instituto Brasileiro de Geografia e Estatística, 2019).

\subsection{A pesquisa de campo e a caracterização dos assentamentos rurais}

Esta pesquisa contou com uma amostra intencional não probabilística. Foram objeto de estudo desta pesquisa exploratória famílias de assentamentos rurais, comerciantes locais e presidentes de associações de assentamentos situados na microrregião de Araguaína, território no entorno do Bico do Papagaio, norte do estado de Tocantins. Além do coordenador da pesquisa, este trabalho contou com o apoio da equipe técnica do Instituto de Desenvolvimento Rural do Tocantins (Ruraltins).

Dado o caráter qualitativo e exploratório desta pesquisa, os dados foram coletados em duas fases, no biênio 2016-2018. A primeira fase correspondeu ao pré-teste do roteiro de entrevistas semiestruturado, que serviu de base para o roteiro aplicado na segunda fase. Do total de 93 famílias entrevistadas entre pré-teste e pesquisa definitiva, foram consideradas apenas as entrevistas completas, totalizando 78 famílias, uma população de quase 400 pessoas em 12 assentamentos rurais.

Os municípios cobertos pela pesquisa de campo foram: Araguaína, Babaçulândia, Piraquê e Wanderlândia. Araguaína representa a maior parte da amostra das famílias entrevistadas (37,2\%), seguida dos municípios de Piraquê (28,2\%), Babaçulândia (20,5\%) e Wanderlândia $(14,1 \%)$. A Figura 1 apresenta o mapa de localização da microrregião de Araguaína, onde foi realizada a pesquisa. 


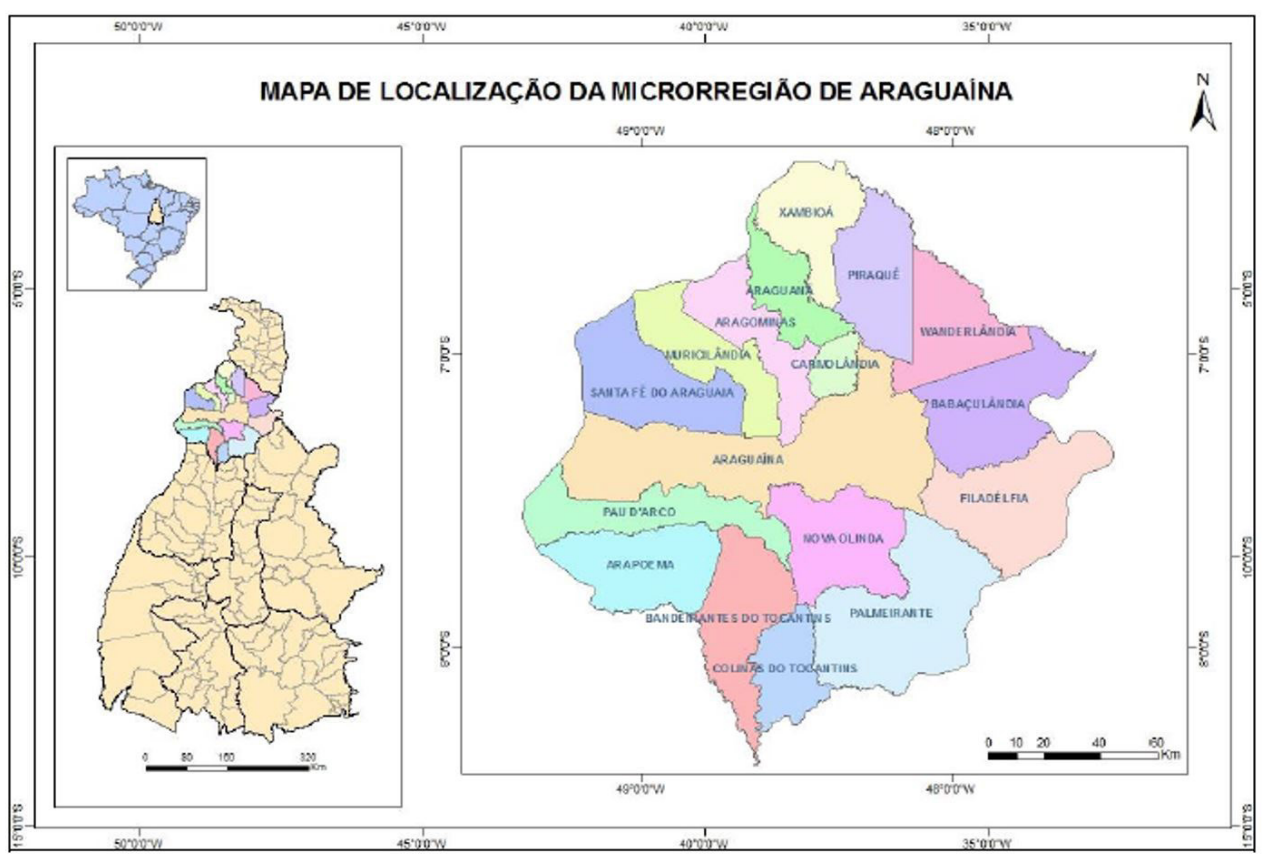

Figura 1: Localização da microrregião geográfica de Araguaína. Fonte: Guedes \& Brito (2014, p. 95).

De acordo com o Relatório Geral dos Assentamentos da Reforma Agrária (Instituto Nacional de Colonização e Reforma Agrária, 2018), havia aproximadamente 23.446 famílias em 379 assentamentos rurais existentes no estado de Tocantins. Estima-se que há cerca de 1.976 famílias em 28 assentamentos rurais dos municípios cobertos pela pesquisa. A maioria dos assentamentos rurais visitados é proveniente do Projeto de Assentamento Federal do Instituto Nacional de Colonização e Reforma Agrária (INCRA), de Reassentamento de Barragem do Consórcio Estreito de Energia (CESTE), do Projeto de Assentamento Estadual do Governo do Tocantins e do Programa Nacional de Crédito Fundiário (PNCF).

Dada a grande extensão de terras nessa região, a maioria dos assentamentos rurais está situada em locais remotos com precárias condições das estradas, que mais parecem trilhas, longe dos centros urbanos e da BR-153 (Rodovia Belém-Brasília) - principal via de comunicação da região. Pôde-se verificar a precariedade da infraestrutura de um modo geral, envolvendo a falta de saneamento básico, escolas rurais, energia elétrica, coleta de lixo, segurança pública, postos de saúde, entre outros serviços públicos.

A maior parte dos assentamentos rurais tem como principal atividade econômica a agricultura de subsistência, envolvendo a produção de farinha de mandioca, feijão, criação de suínos e galináceos. Em vários domicílios, foi possível entrevistar quebradeiras de coco, que sustentam a família a partir de atividades extrativas de pequi, castanhas, coco de babaçu, buriti, murici, entre outros frutos amazônicos. As péssimas condições das vias de comunicação encarecem a comercialização dos produtos agrícolas, inviabilizando a produção em maior escala e a integração desses assentamentos rurais com os mercados da agricultura familiar.

Crimes de pistolagem são os eventos com maior incidência e nível de gravidade nesses assentamentos rurais por conta dos conflitos por terra e exploração ilegal de madeira por grileiros (Comissão Pastoral da Terra, 2019). Nessa região, são frequentes e numerosos os relatos de despejos violentos de posseiros de terra. Esses acontecimentos têm um efeito devastador na vida econômica das famílias quando resultam na perda ou destruição de ativos, como sugerem alguns estudos sobre vulnerabilidades e riscos no contexto da pobreza. 
A precariedade ou a ausência de serviços públicos nesses assentamentos rurais agravam as condições de vida das famílias pobres. Nos termos de Sen (2010), nessa situação, a privação de liberdade dessas famílias vincula-se à carência de serviços públicos, limitando oportunidades sociais e econômicas na atividade agrícola.

\subsection{Mensuração da taxa de desconto}

A fim de identificar vieses cognitivos no processo decisório das famílias pobres, foram mensuradas preferências temporais ao solicitar aos entrevistados que escolhessem entre receber uma gratificação monetária imediata ou uma gratificação monetária futura, exercício comum na literatura relacionada ao assunto (Karlan et al., 2006; Cole et al., 2010). Nesse sentido, foram adotados os seguintes quadros de escolha intertemporal (time frame):

a) Você prefere receber $\mathrm{R} \$ 80,00$ hoje ou $\mathrm{R} \$ 110,00$ daqui a um mês?

b) Você prefere receber $R \$ 80,00$ daqui a seis meses ou $R \$ 110,00$ daqui a sete meses?

A primeira questão foi classificada como quadro de escolhas de curto prazo (near-time frame choice), e a segunda, como quadro de escolhas mais distantes (distant frame choice).

Para casos em que o montante ofertado de $R \$ 110,00$ não era suficiente para que o respondente se dispusesse a abrir mão da gratificação imediata de $R \$ 80,00$, as perguntas foram as seguintes:

a) Se preferir não receber $R \$ 80,00$ hoje, quanto estaria disposto a receber daqui a um mês?

b) Se preferir não receber $R \$ 80,00$ em seis meses, quanto estaria disposto a receber daqui a sete meses?

Posto isto, para inferir taxas de desconto a partir de escolhas intertemporais, este trabalho utilizou a relação entre a gratificação imediata ou valor presente de um fluxo de caixa, denotado por $P$, e sua gratificação futura ou valor futuro, denotado por $F$ (Frederick et al., 2004; Cole et al., 2010; Urminsky \& Zauberman, 2015). Formalmente,

$$
F=P(1+R)^{t}
$$

Em que: $R$ é a taxa de desconto e té o tempo de espera pela gratificação ou recompensa. As variáveis $P$ e $t$ são dadas nas questões de preferências intertemporais, conforme apresentado anteriormente. Assim sendo, a taxa de desconto será dada por:

$R=\left(\frac{F}{P}\right)^{(1 / t)}-1$

Segundo Wang et al. (2016), essa é a abordagem clássica para mensuração da taxa de desconto, amplamente utilizada na literatura acerca do assunto.

\section{Resultados e discussão}

Nesta seção, serão apresentados os resultados do levantamento de campo realizado nos assentamentos rurais no norte do estado de Tocantins. Os dados coletados nesta pesquisa e a discussão baseada na análise dos estudos empíricos anteriores permitiram uma melhor caracterização da vida econômica e dos padrões de escolha intertemporal das famílias que vivem em condição de pobreza. 


\subsection{Condições socioeconômicas dos assentados}

Sendo a renda a variável consagrada para mensurar pobreza, ao analisar o rendimento familiar dos assentados, conforme Tabela 1, verificou-se que $41,1 \%$ dos entrevistados declararam ganhar até 1 salário mínimo por mês, 26,4\%, entre 1 e 3 salários, e 2,6\%, entre 3 e 5 salários mínimos. De acordo com a Pesquisa Nacional por Amostra de Domicílios (Instituto Brasileiro de Geografia e Estatística, 2015), no Tocantins, 34,4\% da população ganhava até 1 salário mínimo, 29,4\%, entre 1 e 5 salários, e 36,1\%, acima de 5 salários mínimos.

Tabela 1 - Classes de rendimento mensal (\%)

\begin{tabular}{lcc}
\multicolumn{1}{c}{ Categoria } & Amostra de campo* & $\begin{array}{c}\text { Estimativa populacional da } \\
\text { PNAD }\end{array}$ \\
Até 1/2 salário mínimo & 10,3 & 9,5 \\
Mais de 1/2 a 1 salário mínimo & 30,8 & 24,9 \\
Mais de 1 a 2 salários mínimos & 13,6 & 19,9 \\
Mais de 2 a 3 salários mínimos & 12,8 & 5,0 \\
Mais de 3 a 5 salários mínimos & 2,6 & 4,5 \\
Acima de 5 salários mínimos** & - & 36,1 \\
Total & $\mathbf{7 8}$ & $\mathbf{1 . 2 9 0 . 0 0 0}$ \\
\hline
\end{tabular}

Fontes: dados da pesquisa de campo e dados da PNAD (Instituto Brasileiro de Geografia e Estatística, 2015). Nota: * Classificação feita a partir do salário mínimo nacional no ano de 2017. ** Não foram encontrados indivíduos (chefes de família) com rendimentos acima de 5 salários mínimos na pesquisa de campo.

Verificou-se que a média de pessoas que auferiam renda era de 1,9 por domicílio. É importante ressaltar que a menção da renda auferida em termos de salários mínimos é apenas uma estimativa não exata dos ganhos. Muitas famílias dependiam de diferentes fontes de renda para sua sobrevivência, ganhando mais renda em um período e menos em outro. Portanto, a irregularidade e a incerteza na renda agravam os problemas de sobrevivência das famílias pobres no meio rural, sendo fontes de riscos para elas (Collins et al., 2009; Morduch \& Schneider, 2017).

A Tabela 2 indica que 5,1\% das famílias de assentados entrevistadas viviam na extrema pobreza, ou seja, tinham renda familiar per capita mensal de até $\mathrm{R} \$ 85,00$. Aproximadamente, $21,8 \%$ tinham renda per capita mensal entre $\mathrm{R} \$ 85,00$ e $\mathrm{R} \$ 170,00$ (pobreza), e $48,7 \%$, renda familiar per capita entre $\mathrm{R} \$ 170,00$ e $\mathrm{R} \$ 484,00$ (baixa renda) ${ }^{5}$.

Tabela 2 - Renda familiar mensal per capita

\section{Categoria}

\begin{tabular}{lc} 
Até $R \$ 85,00(\mathrm{em} \%)$ & 5,1 \\
Entre $\mathrm{R} \$ 85,00$ e $\mathrm{R} \$ 170,00(\mathrm{em} \%)$ & 21,8 \\
Entre $\mathrm{R} \$ 170,00$ e $\mathrm{R} \$ 484,00(\mathrm{em} \%)$ & 48,7 \\
Acima de $\mathrm{R} \$ 484,00(\mathrm{em} \%)$ & 24,4 \\
Média (em $\mathrm{R} \$$ ) & 338,71 \\
Mediana (em $R \$)$ & 226,77 \\
\hline
\end{tabular}

Fonte: dados da pesquisa de campo.

É importante destacar que, ainda que se adote o critério de renda para mensurar pobreza, tal medida é insuficiente para lidar com aspectos mais gerais das condições de escassez e

${ }^{5}$ Como no Brasil ainda não há uma linha oficial de pobreza, optou-se, à época de edição deste trabalho, pela adoção das faixas de rendimento em reais definidas pelo Programa Bolsa Família a partir do Decreto n 8.794 , de 29 de junho de 2016, do governo federal. 
necessidades básicas. Nesta perspectiva, o acesso aos serviços públicos e as condições de moradia também são importantes indicativos da situação de vulnerabilidade das famílias, sobretudo os serviços na esfera do saneamento básico, como abastecimento de água por rede geral, esgotamento sanitário e coleta de lixo.

Além da pobreza monetária, foram investigados outros aspectos multidimensionais da pobreza relacionados às condições de vida das pessoas. Na pesquisa de campo, verificou-se que a maioria das residências $(83,4 \%)$ não estava ligada à rede geral de distribuição de água. Poços, rios e açudes foram as principais fontes de abastecimento de água, sendo comum o carregamento de água em baldes e galões plásticos pelas famílias. As péssimas condições de armazenamento de água observadas em várias residências implicavam potenciais fontes de contaminação.

O acesso ao escoamento sanitário é ainda mais precário. Pôde-se verificar que em um pouco mais da metade das residências $(51,3 \%)^{6}$ o escoamento sanitário era feito a partir de fossa rudimentar ou vala a céu aberto construída pelos próprios assentados. Do total da amostra, em $48,7 \%$ dos domicílios não havia coleta de lixo. Na maior parte das vezes, o lixo era jogado em terrenos baldios, dado que eram poucas as famílias que aterravam ou queimavam o lixo em sua propriedade.

No que tange às condições de moradia, do total de 78 domicílios visitados, verificou-se que $55,1 \%$ das casas dos assentados eram de alvenaria, $20,5 \%$, de palha, $14,1 \%$, de madeira, e $10,2 \%$, de outros materiais, tais como adobe ${ }^{7}$ e lona. Pouco mais da metade das residências (51,3\%) tinha entre dois e três cômodos, com adensamento habitacional excessivo, ou seja, a presença de mais de três moradores por cômodo. No interior de várias delas, o piso era de terra batida.

As precárias condições sanitárias e de moradia observadas evidenciam um sério problema de insalubridade, o que pode justificar a alta incidência de doenças tropicais na região dos assentamentos rurais ${ }^{8}$. Nisso, o quadro mais preocupante é a alta vulnerabilidade das famílias pobres a essas doenças, ocasionando perda de renda do trabalhador rural.

Destaca-se que, na maioria dos assentamentos rurais visitados, não havia escolas rurais $(91,7 \%)$. A ausência delas na região, a falta de programas de extensão rural e o baixo grau de instrução dos assentados são fatores que limitam a atividade econômica das famílias. Nesse caso, à luz da abordagem de Sen (2010), evidencia-se claramente a ausência de oportunidades econômicas configuradas no baixo grau de instrução dos entrevistados. Em outros termos, a "falta de leitura" dos entrevistados limita o seu campo de possibilidades de inserção em programas governamentais de aquisição de alimentos ou de financiamentos para agricultura familiar.

\subsection{Necessidades financeiras, poupança e outros mecanismos de enfrentamento}

No contexto do desenvolvimento econômico, a poupança é um importante instrumento de proteção social, pois permite mais atividades geradoras de renda, controle de consumo, planejamento financeiro e proteção contra os choques. Isso pode garantir liberdade econômica, gerando um ciclo virtuoso no processo de desenvolvimento individual, como defendem Amartya Sen (2010) e Dean Karlan et al. (2013).

${ }^{6}$ Os sanitários dessas propriedades são compostos apenas de um buraco para dejeções, o que evidencia um sério problema de insalubridade.

7 Trata-se de tijolos de terra, água e palha ou fibras naturais moldadas de forma rudimentar pelos assentados. São casas de barro que, em algumas regiões, são chamadas também de casa de pau a pique.

${ }^{8}$ Febre amarela, dengue, febre Chikungunya, doença de Chagas e leishmaniose, esta última popularmente conhecida na região como calazar, foram as doenças mais citadas pelos entrevistados. 
Na pesquisa de campo, verificou-se que cerca de $37,2 \%$ das famílias tinham caderneta de poupança. Emergências de saúde (17,2\%), transações de compra e venda de animais (13,8\%) e recebimento de benefícios sociais $(13,8 \%)$ foram os principais motivos para a manutenção da conta poupança.

Por outro lado, a maioria das famílias $(62,8 \%)$ não dispunha de caderneta de poupança. Insuficiência de renda (77,6\%), baixos rendimentos da aplicação $(8,2 \%)$, falta de instrução financeira $(8,2 \%)$, desconfiança no sistema bancário $(4,1 \%)$ e elevados custos de transação (2\%) foram as principais barreiras a poupar para essas famílias. Essas evidências também foram constatadas nos estudos empíricos de Collins et al. (2009), Banerjee \& Duflo (2012), Morduch \& Schneider (2017) e Rutherford (1999).

A renda média familiar per capita das famílias com caderneta de poupança foi de aproximadamente $R \$ 437,20$. As famílias poupadoras, mesmo em situação de pobreza absoluta ${ }^{9}$, auferiam renda de quase $94 \%$ a mais em relação às famílias que não dispunham desse mecanismo financeiro ( $R \$ 225,42)$. Portanto, as famílias que não tinham caderneta de poupança estavam nas faixas inferiores da renda familiar per capita, ou seja, em situação de extrema pobreza.

No campo, foi possível entrevistar proprietários de mercearias nos centros urbanos dos municípios cobertos pela pesquisa que guardavam dinheiro dos assentados em seus estabelecimentos. Esse tipo de poupança informal, geralmente, é utilizado por beneficiários rurais do Programa Bolsa Família para pagamento de credores e proteção dos poucos recursos, dada a alta incidência de crimes nos assentamentos rurais da região.

Portanto, os resultados desta pesquisa corroboram estudos anteriores acerca do processo de exclusão financeira dos pobres (Rutherford, 1999; Crocco et al., 2013; Anderloni \& Carluccio, 2006), mostrando que, embora os assentados tivessem acesso ao sistema bancário, eles encontravam alternativas para atender às suas demandas financeiras de acordo com os serviços que estavam ao seu alcance.

Por outro lado, a poupança não monetária era largamente utilizada pelas famílias, merecendo destaque para a compra de animais de pequeno e médio porte, como um dos principais mecanismos de enfrentamento. Na região em que foi realizada a pesquisa, era comum no período da seca e em situações de emergência que os animais fossem vendidos a um preço abaixo do mercado por causa da impossibilidade das famílias de alimentá-los. A falta de acesso às fontes estáveis de financiamento de curto prazo torna real o risco de perda desses ativos. Todos os anos, esse processo de descapitalização de ativos se repete. O Quadro 1 resume os resultados da pesquisa.

Portanto, a realização de poupança não monetária é para as famílias pobres uma forma de garantir sua sobrevivência diária. Vale dizer que a referida modalidade de poupança não garante oportunidade econômica e proteção social que gere um ciclo virtuoso de bem-estar material no processo de desenvolvimento individual (Sen, 2010; Dupas \& Robinson, 2013). Isso porque, ao considerar a situação de pobreza dessas famílias, a poupança não monetária atende às suas necessidades específicas de curtíssimo prazo. Dadas as necessidades prementes, o foco dessas famílias está voltado para o presente.

${ }^{9}$ O Instituto de Pesquisa Econômica Aplicada (IPEA) define a condição de pobreza extrema quando o rendimento médio mensal per capita for de até $1 / 4$ do salário mínimo; pobreza absoluta quando o rendimento médio mensal per capita for de até 1/2 salário mínimo; e de pobreza quando o rendimento médio mensal per capita for até 1 salário mínimo. O leitor interessado poderá consultar Instituto de Pesquisa Econômica Aplicada (2010). 
Quadro 1 - Necessidades financeiras e mecanismos de enfrentamento

\section{Eventos}

Emergências
Tipos de despesas

Gastos médicos
Eventos do ciclo Morte

de vida

Eventos sazonais

Outros eventos
Imposto territorial rural

\section{Material escolar}

Falência de pequenos negócios

Violência doméstica

Quebra de safra (seca)

Conflitos agrários (pistolagem)

Doenças no rebanho

Estelionato (fraudes)

Problemas com a justiça

\section{Mecanismo de enfrentamento}

Amigos e parentes

Empréstimo bancário

Caderneta de poupança

Agiota

Cheque especial

Venda de animais

Poupança doméstica

Venda antecipada da colheita

Empréstimo com o empregador

Empréstimo bancário

Venda de animais

Lista na vizinhança

Venda de animais

Cheque especial

Amigos e parentes

Lista na vizinhança

Empréstimo bancário

Venda de animais

Mutirão

Cheque especial

Renegociação de crédito (PRONAF)

Fonte: dados da pesquisa de campo.

\subsection{Padrões de escolha intertemporal}

Como visto, uma crescente literatura em economia comportamental sugere que a pobreza distorce a tomada de decisão econômica, conduzindo os pobres à situação de subpoupança. Essa literatura atribui a não realização de poupança das famílias pobres à tendência de valorizar o bem-estar no tempo presente em detrimento do futuro - o chamado viés do presente, também denominado impaciência (Mullainathan \& Shafir, 2013; Mani et al., 2013; Haushofer \& Fehr, 2015).

Nesta perspectiva, a fim de identificar vieses no processo decisório das famílias pobres, foram mensuradas preferências temporais ao solicitar aos entrevistados que escolhessem hipoteticamente entre receber uma gratificação monetária imediata ou uma gratificação monetária futura, exercício comum na literatura relacionada ao assunto, como apresentado na Tabela $3^{10}$.

Tabela 3 - Perfil dos assentados segundo preferências intertemporais

\begin{tabular}{|c|c|c|}
\hline Categorias & Perfis & $(\%)$ \\
\hline \multirow[t]{2}{*}{ Escolhas de curto prazo (hoje ou daqui a um mês?) } & Pacientes & 24,7 \\
\hline & Impacientes & 75,3 \\
\hline \multirow[t]{2}{*}{ Escolhas mais distantes (daqui a 6 meses ou daqui a 7 meses?) } & Pacientes & 20,8 \\
\hline & Impacientes & 79,2 \\
\hline Total & & 77 \\
\hline
\end{tabular}

Fonte: dados da pesquisa de campo.

${ }^{10}$ O leitor deve notar que, nas Tabelas 3 e 4 sobre escolha intertemporal, há apenas 77 famílias entrevistadas em vez de 78, conforme consta na Tabela 1. Por causa do estado emocional fragilizado de um chefe de família em situação de extrema pobreza e fome, decidiu-se não dar continuidade à entrevista semiestruturada em respeito ao entrevistado. Portanto, as questões que envolviam os temas de escolha intertemporal, aspirações e perspectiva de futuro não foram completadas no formulário de entrevista. 
As questões implicam uma taxa de desconto, isto é, trata-se da taxa em que o indivíduo se mostra disposto a abrir mão de uma gratificação imediata em prol de uma gratificação monetária futura. Os resultados revelam uma grande dose de impaciência dos entrevistados em relação ao futuro, seja o futuro próximo, seja o futuro mais distante. Os resultados sugerem que os assentados são pouco previdentes, ou seja, são movidos pelas necessidades mais prementes e, portanto, descontam o futuro a taxas elevadas.

É surpreendente mesmo que esse grau de impaciência aumente em relação às escolhas de prazos mais distantes. Como se observa na Tabela 3, quando os indivíduos foram chamados a comparar o prazo de seis meses com o de sete meses, a porcentagem de impacientes aumentou $(79,2 \%)$ comparativamente à escolha de curto prazo em que o indivíduo foi chamado a comparar a gratificação imediata com a de um mês (75,3\%). Constata-se, assim, um padrão diferente daquele observado em pesquisas anteriores, em que a taxa de desconto futuro tende a decrescer em relação às escolhas em prazos distantes (Laibson, 1977; Loewenstein \& Prelec, 1992).

Como interpretar esses resultados à luz da economia comportamental? Como discutido na literatura, a pobreza não se resume à escassez de recursos, mas inclui, além disso, e talvez até principalmente, um imposto cognitivo. O ambiente de escassez, a privação de capacitações para se realizar determinados funcionamentos e a precária infraestrutura rural, somando-se às inúmeras decisões difíceis no cotidiano, podem potencializar o esgotamento cognitivo das famílias (Mullainathan \& Shafir, 2013; Mani et al., 2013).

A Tabela 4 apresenta a classificação dos entrevistados em diferentes categorias de preferências intertemporais e taxas de desconto.

Tabela 4 - Perfil dos assentados segundo preferências intertemporais e taxas de desconto

\begin{tabular}{|c|c|c|c|c|}
\hline Categorias & Perfis & $\begin{array}{l}\text { Entrevistados } \\
\qquad(\%)\end{array}$ & $\begin{array}{l}\text { Taxa média de } \\
\text { desconto futuro } \\
\text { próximo (\%) }\end{array}$ & $\begin{array}{l}\text { Taxa média de } \\
\text { desconto futuro } \\
\text { distante (\%) }\end{array}$ \\
\hline \multirow[t]{2}{*}{ Viés do presente } & $\begin{array}{l}\text { Impacientes no } \\
\text { presente e no futuro }\end{array}$ & 40,3 & 245,6 & 380,4 \\
\hline & $\begin{array}{l}\text { Impacientes no } \\
\text { presente e pacientes } \\
\text { no futuro }\end{array}$ & 28,6 & 554,6 & 11,4 \\
\hline $\begin{array}{l}\text { Reversão de } \\
\text { preferências }\end{array}$ & $\begin{array}{l}\text { Pacientes no presente } \\
\text { e impacientes no } \\
\text { futuro }\end{array}$ & 23,4 & 3,47 & 179,7 \\
\hline $\begin{array}{l}\text { Preferências } \\
\text { voltadas para o } \\
\text { futuro }\end{array}$ & $\begin{array}{l}\text { Pacientes no presente } \\
\text { e no futuro }\end{array}$ & 7,8 & 0,0 & 0,0 \\
\hline Total (N) & & 77 & & \\
\hline
\end{tabular}

Fonte: dados da pesquisa de campo.

O modelo de utilidade com desconto constante pressupõe preferências de tempo consistentes usando uma função de desconto exponencial. Isso implica que a preferência temporal entre quaisquer períodos adjacentes deve ser constante, o que não se observou para a maioria dos entrevistados (92,2\%), conforme a Tabela 4. Portanto, no que tange à inconsistência intertemporal, os resultados desta pesquisa são condizentes com os estudos empíricos anteriores (Thaler, 1981; Benzion et al.1989; Wang et al., 2016).

O nível de impaciência observado na amostra foi alto, pois quase $69 \%$ dos entrevistados apresentaram preferências voltadas para o presente. Esse resultado pode ser atribuído às condições de escassez, como se depreende de fragmentos de frases do tipo: "Preciso do 
dinheiro agora por conta da precisão: falta óleo, sal, feijão. Tenho que deixar de comer para dar para os meus filhos(sic)", diz uma entrevistada ao relatar a falta de produtos de primeira necessidade em sua residência. A impaciência também foi expressa por um chefe de família nos seguintes termos: "A gente tá com fome hoje. Tá faltando arroz, feijão e óleo em casa. Não posso esperar (sic)".

Como visto, a pobreza parece gerar um foco intenso sobre o presente em detrimento do futuro. Quando parte dessas famílias direciona seus recursos mentais para lidar com preocupações da pobreza - por exemplo, pagamento de dívidas, insuficiência de renda e escassez de alimentos -, elas devotam menos atenção para outras questões importantes, tais como saúde, educação e até mesmo a realização de poupança. Portanto, conjectura-se que o viés do presente, potencializado pela condição de pobreza, pode explicar em alguma medida a baixa poupança das famílias assentadas. Tais resultados corroboram as análises de Ashraf et al. (2006) e Dupas \& Robinson (2013).

$\mathrm{Na}$ Tabela 4 , verifica-se que $28,6 \%$ dos entrevistados se mostraram impacientes no presente e pacientes no futuro. Essas pessoas descontam ganhos futuros hiperbolicamente, com taxas médias de desconto para o futuro próximo $(554,6 \%$ ) muito elevadas em relação ao futuro distante $(11,4 \%)$. Em outros termos, esses assentados adotavam uma taxa de retorno muito alta para descontar no futuro quando confrontados com a situação presente, mas estavam dispostos a reduzir essa taxa quando sua escolha fosse adiada. É um resultado interessante e que está de acordo com algumas pesquisas empíricas (O'Donoghue \& Rabin, 2014; Frederick et al., 2004, Ashraf et al., 2006). Por outro lado, 40,3\% dos indivíduos apresentavam taxas médias de desconto mais elevadas no futuro distante $(380,4 \%)$ do que no futuro próximo $(245,6 \%)$.

Chama atenção nos resultados da Tabela 4 que 23,4\% dos entrevistados apresentaram reversão de preferências. Eram indivíduos caracterizados como pacientes no presente e impacientes no futuro. Observa-se que uma das explicações potenciais que justifica esse padrão de escolha pode estar associada às estações climáticas da região. A maioria dos entrevistados desse grupo expressou uma forte preocupação com o período de estiagem, que, coincidentemente, ocorreria nos seis meses posteriores ao período da pesquisa. O período da seca representa para os agricultores o risco da fome, como resultado da queda da produção agrícola e redução da renda familiar.

Portanto, pode-se dizer que a preferência por ganhos presentes, ainda que com valores menores, conduz à incapacidade de planejar o futuro, o que leva a dificuldades de realização de poupança por parte dessas famílias. Como sugerido por Rabin (1998), acredita-se que é muito mais provável que o viés do presente também esteja associado a uma incapacidade do indivíduo em visualizar o futuro distante.

\section{Considerações finais}

No Brasil, a pesquisa comportamental ainda é pouco utilizada na formulação das políticas públicas. As descobertas empíricas recentes podem contribuir para que os economistas brasileiros avancem sobre um novo conjunto de abordagens do desenvolvimento, tendo em vista os estudos de campo para o combate à pobreza.

As características da referida população e as variáveis que afetam sua escolha temporal foram estudadas sem a pretensão de uma análise aprofundada das relações de causalidade envolvidas no ambiente decisório. Apesar dos desafios metodológicos da pesquisa, buscouse oferecer uma explicação complementar dos desafios da pobreza em termos dos vieses cognitivos potencializados pela condição de escassez, contribuindo, assim, para a ainda incipiente literatura de economia comportamental do desenvolvimento no Brasil. 
Neste contexto, verificou-se que a poupança não monetária era amplamente utilizada pelas famílias para atender às suas necessidades de curtíssimo prazo. No entanto, essa modalidade de poupança não se traduz em investimentos que possam garantir o rompimento do ciclo vicioso da pobreza ao longo do tempo.

Constatou-se que a maioria dos entrevistados apresentou um padrão de preferências intertemporais diferente daquele observado em pesquisas empíricas anteriores, em que a taxa de desconto futuro tendia a decrescer ao longo do tempo. De um modo geral, tanto no quadro de escolhas de curto prazo como no quadro de escolhas distantes, os indivíduos apresentaram preferências voltadas para o presente, e esse padrão não se alterava quando o momento da escolha era adiado.

As evidências de campo revelaram que as pessoas que viviam em condições de extrema pobreza tinham dificuldades de visualizar oportunidades potenciais no horizonte, dado a intensidade do viés do presente. Essas restrições internas comprometiam a tomada de decisão em relação à poupança, reforçando os elos de uma engrenagem que levava as famílias ao endividamento junto aos credores informais, descapitalização de ativos e gastos dos recursos provenientes da poupança não monetária para atender às necessidades de curtíssimo prazo.

A isso, soma-se a privação de liberdade das famílias vinculada à falta de oportunidade econômica, insuficiência de recursos e não acesso aos serviços públicos essenciais. A falta desses bens públicos pode ser uma das fontes de perpetuação da pobreza, por conta da alta incidência de doenças causadas pelas precárias condições sanitárias, que acarretam perda de renda. Ademais, o não acesso à educação ou baixo grau de instrução dos assentados e a falta de programas de extensão rural efetivos implicavam dificuldades em integrá-los aos mercados da agricultura familiar.

Ao reconhecer as limitações do presente trabalho, sugere-se em pesquisas futuras o aprofundamento do conhecimento existente sobre a pobreza multidimensional nas condições brasileiras e nas várias regiões que integram o país. Há ainda poucas evidências sobre o efeito causal que diferentes intervenções de política pública de combate à pobreza têm sobre o bemestar psicológico e a capacidade de decisão econômica dos seus beneficiários. A dimensão temporal permanece inexplorada no contexto da pobreza. Não se sabe se a amenização da pobreza leva a um aumento permanente ou transitório no bem-estar psicológico, melhorando a tomada de decisão em condições de campo.

De forma pragmática, são necessários novos trabalhos que investiguem se, de fato, as sobrecargas cognitivas e emocionais da pobreza podem ser amenizadas a partir de políticas sociais que busquem gerar níveis mínimos de proteção social, contribuindo para a formulação de políticas públicas mais efetivas. Na perspectiva da economia comportamental, essas políticas podem ser imprescindíveis para oportunizar a expansão das aspirações e a redução dos níveis de estresse, ampliando, assim, a capacidade de tomada de decisão das pessoas que vivem em privação no mundo econômico real.

\section{Referências}

Abramovay, R. (Ed.). (2004). Laços financeiros na luta contra a pobreza. São Paulo: Annablume.

Aleem, I. (1990). Imperfect information, screening, and the costs of informal lending: a study of a rural credit market in Pakistan. The World Bank Economic Review, 4(3), 329-349.

Alsop, R., Bertelsen, M. F., \& Holland, J. (2006). Empowerment in practice: from analysis to implementation. Washington, D.C.: World Bank Directions in Development. 
Anderloni, L., \& Carluccio, E. M. (2006). Access to bank accounts and payment services. In L. Anderloni, M. D. Braga \& E. M. Carluccio (Eds.), New Frontiers in banking services: emerging needs and tailored products for untapped markets. New York: Springer.

Appadurai, A. (2004). The capacity to Aspire: culture and the terms of recognition. In V. Rao \& M. Walton (Eds.), Culture and public action. Washignton: Standford University Press.

Ashraf, N., Karlan, D., \& Yin, W. (2006). Tying Odysseus to the Mast: evidence from commitment savings products in the Philippines. The Quarterly Journal of Economics, 121(2), 635-672.

Banerjee, A., \& Mullainathan, S. (2010). The Shape of Temptation: Implications for the Economic Lives of the Poor. NBER Working Paper, 15973.

Banerjee, A., \& Duflo, E. (2012). A economia do pobres: repensar de modo radical a luta contra pobreza. Lisboa: Temas \& Debates.

Baumeister, R. F., Bratslavky, E., Muraven, M., \& Tice, D. M. (1998). Ego depletion: is the active self a limited resource? Journal of Personality and Social Psychology, 74(5), 1252-1265.

Benzion, U., Rapoport, A., \& Yagil, J. (1989). Discount rates inferred from decisions: an experimental study. (2014). Management Science, 35(3), 270-284.

Bertrand, M., Mullainathan, S., \& Shafir, E. (2004). A behavioral economics view of poverty. The American Economic Review, 94(1), 419-423.

Bianchi, A. M. (2018). O tempo das escolhas. Recuperado em 18 de setembro de 2018, de http:// www.economiacomportamental.org/blog/

Breton, B. L. (2002). Todos sabiam: a morte anunciada do Padre Josimo(1. ed.). São Paulo: Loyola.

Carneiro, A., \& Cioccari, M. (2010). Retrato da política de repressão no campo (1962-1985): camponeses torturados, mortos e desaparecidos. Brasília: MDA.

Case, A., \& Deaton, A. (2009). Health and well-being in Udaipur and South Africa. In D. A. Wise (Ed.), Developments in the economics of aging (317 p.). University of Chicago Press.

Cavalcante, M. E. S. R. (1999). Tocantins: o movimento separatista do Norte de Goiás (19211988). Editora UGC.

Chen, E., Cohen, S., \& Miller, G. E. (2010). How low socioeconomic status affects 2-yearhormonal trajectories in children. Psychological Science, 21(1), 31-37.

Cohen, S., Doyle, W. J., \& Baum, A. (2001). Socioeconomic status is associated with stress hormones. Psychosomatic Medicine, 68(3), 414-420.

Cole, S., Sampson, T., \& Zia, B. (2010). Prices or knowledge? What drives demand for financial services in emerging markets? (Working Paper, pp. 9-117). Harvard Business School.

Collins, D., Morduch, J., Ruterford, S., \& Ruthven, O. (2009). Portfolio of the poor: how the world's poor live on two dollars a day. Princeton University Press.

Comissão Pastoral da Terra - CPT. (2019). Conflitos no Campo - Brasil. CPT Nacional.

Crocco, M. A., Santos, F., \& Figueiredo, A. (2013). Exclusão financeira no Brasil: uma análise regional exploratória. Revista de Economia Política, 33(3), 505-526.

Dean, E. B., Schilbach, F., \& Schofield, H. (2017). Poverty and cognitive function. In The economics of poverty trap. Cambridge: National Bureau of Economic Research.

DellaVigna, S. (2009). Psychology and economics: evidence from field. Journal of Economic Literature, 472, 315-372.

Dupas, P., \& Robinson, J. (2013). Why don't the poor save more? Evidence from health savings experiments. The American Economic Review, 103(4), 1138-1171. 
Evans, G. W., Fuller-Rowell, T. E., \& Doan, S. N. (2012). Childhood cumulative risk and obesity: the mediating role of self-regulatory ability. Pediatrics, 129(1), 68-73.

Flechtner, S. (2016). Aspiration and the persistence of poverty and inequalities (Dissertation). Internationatinales Institut für Management und ökonomische Bildung.

Frederick, S., Loewenstein, G., \& O'Donoghue, T. (2004). Time discounting and time preference: a critical review. In C. F. Camerer, G. Loewenstein \& R. Matthew (Eds.), Advances in behavioral economics. Princeton University Press.

Galab, S., Vennam, U., Komanduri, A., Benny, L., \& Georgiadis, A. (2013). The impact of parental aspirations on private school enrollment: evidence from Andhra Pradesh, India (Young Lives Working Paper, No. 97).

Guedes, L. S. G., \& Brito, J. L. S. (2014). Caracterização socioeconômica da microrregião de Araguaína. Observatorium. Revista Eletrônica de Geografia, 6(17), 91-103.

Haushofer, J., \& Fehr, E. (2015). Sobre a psicologia da pobreza. In A. M. Bianchi \& F. Àvila (Eds.), Guia de economia comportamental e experimental (1. ed., pp. 140-155). São Paulo: Economia Comportamental.

Haushofer, J., \& Shapiro, J. (2013). Household response to income changes: evidence from an unconditional cash transfer program in Kenya (Working Paper). Massachusetts Institute of Technology.

Instituto Brasileiro de Geografia e Estatística - IBGE. (2015). Pesquisa nacional por amostra de domicílios. Rio de Janeiro: IBGE.

Instituto Brasileiro de Geografia e Estatística - IBGE. (2019). Síntese dos indicadores sociais. Rio de Janeiro: IBGE.

Instituto de Pesquisas Data Folha. (2017). Pesquisa sobre imediatismo brasileiro. Folha de São Paulo. São Paulo, Recuperado em 25 de janeiro de 2018, de http://www1.folha.uol.com. br/mercado/2017/12/1942232-levantamento-revela-imediatismo-e-baixa-tendencia-apoupanca-do-brasileiro.shtml.

Instituto de Pesquisa Econômica Aplicada - IPEA. (2010). Dimensão, evolução e projeção da pobreza por região e por estado no Brasil(Comunicados do IPEA, No. 58). Recuperado em 5 de julho de 2021, de http://repositorio.ipea.gov.br/bitstream/11058/5293/1/Comunicados_ n58_Dimens\%c3\%a3o.pdf

Instituto Nacional de Colonização e Reforma Agrária - INCRA. (2018). Relatório geral dos assentamentos da reforma agrária. Recuperado em 7 de setembro de 2017, de http:// painel.incra.gov.br/sistemas/index.php

Kahneman, D. (2012). Rápido e devagar: duas formas e pensar (1. ed.). São Paulo: Objetiva.

Karlan, D., Ratan, A. L., \& Zinman, J. (2013). Savings by and for the poor: a research review and agenda (Economic Growth Center Discussion Paper, No. 1027).

Karlan, D., Yin, W., \& Ashraf, N. (2006). Tying odysseus to the mast: evidence from a commitment savings product in the Philippines. The Quarterly Journal of Economics, 121(2), 635-672.

Laibson, D. (1977). Golden eggs and hyperbolic discounting. The Quarterly Journal of Economics, 62(2), 443-478.

Lehto, E., Konttinen, H., Jousilahti, P., \& Haukkala, A. (2013). The role of psychosocial factors in socioeconomic differences in physical activity: a population-based study. Scandinavian Journal of Public Health, 41(6), 553-559. 
Li, L., Power, C., Kelly, S., Kirschbaum, C., \& Hertezman, C. (2007). Life-time socio-economic position and cortisol patterns in mid-life. Psychoneuroendocrinology, 32, 824-833.

Loewenstein, G., \& Prelec, D. (1992). Anomalies in intertemporal choice: evidence and interpretation. In G. Loewenstein \& J. Elster (Eds.), Choice over time (pp. 119-146). New York: Russell Sage Foundation.

Lupien, S. J., King, S., Meaney, M. J., \& McEwan, B. S. (2001). Can poverty get under your skin? Basal cortisol levels and cognitive function in children from low and high socioeconomic status. Development and Psychopathology, 2001(13), 651-674.

Mani, A., Mullainathan, S., Shafir, E., \& Zhao, J. Y. (2013). Poverty impedes cognitive function. Science, (341), 976-980.

Meier, S., \& Sprenger, C. (2009). Discounting Financial Literacy: Time Preferences and Participation in Financial Education Programs (Working paper Microenterprise Program in Zimbabwe: Baseline Findings). Washington: AIMS.

Morduch, J., \& Schneider, R. (2017). The financial diaries: how american families cope in a world of uncertainty. Princeton University Press.

Mullainathan, S., \& Shafir, E. (2013). Scarcity: why having too little means so much (1st ed.). New York: Picador.

Nussbaum, M. (2011). Creating capabilities: the human development approach. Harvard University Press.

O'Donoghue, T., \& Rabin, M. (2014). Doing it now or late. In C. F. Camerer, G. Loewenstein \& R. Matthew (Eds.), Advances in behavioral economics (pp. 222-251). Princeton University Press.

Oliveira, G. A. (2010). Os posseiros e a luta pela terra no Bico do Papagaio 1964/1985: cultura e identidade(Tese de doutorado). Faculdade de Filosofia e Ciências, Universidade Estadual Paulista, Marília.

Oliveira, J. M. M. (2012). Estratégias separatistas e ordenamento territorial: a criação de Palmas na consolidação do estado do Tocantins (Tese de doutorado). Programa de Pós-graduação em Geografia, Universidade Federal de Uberlândia, Uberlândia.

Peretti-Watel, P., L'Haridon, O., \& Seror, V. (2013). Time preferences, socioeconomic status and smokers' behavior, attitudes and risk awareness. European Journal of Public Health, 23(5), 783-788.

Phelps, E. S., \& Pollak, R. A. (1968). On second-best national saving and game-equilibrium growth. The Review of Economic Studies, 35, 185-199.

Quidt, J. \& Haushofer, J. (2016). Depression for economists (Working Paper, No. 22973). National Bureau of Economic Research.

Rabin, M. (1998). Psychology and Economics. Journal of Economic Literature, 36(1), 11-46.

Rutherford, S. (1999). The poor and their money: an essay about financial services for poor people. Institute for Development Policy and Management, University of Manchester.

Sen, A. K. (2010). Desenvolvimento como Liberdade. São Paulo: Companhia das Letras.

Shah, A. K., Mullainathan, S., \& Shafir, E. (2012). Some consequences of having too little. Science, 338, 682-685.

Spears, D. (2011). Economic decision-making in poverty depletes behavioral control. The B.E. Journal of Economic Analysis \& Policy, 11(1). 
Strotz, R. H. (1956). Myopia and inconsistency in dynamic utility maximization. The Review of Economic Studies, 23(3), 165-180.

Thaler, R. (1981). Some empirical evidence on dynamic inconsistency. Economics Letters, (8), 201-207.

Thaler, R. (2015). Misbehavior the making of behavioral economics (pp. 87-98). New York: WW Norton Company.

Urminsky, O., \& Zauberman, G. (2015). The psychology of intertemporal preferences. In G. Wu \& K. Gideon (Eds.), Wiley-Blackwell handbook of judgment and decision making (Vol. II, pp. 141-181). Pondicherry: John Wiley.

Wang, W., Rieger, M. O., \& Hens, T. (2016). How time preferences differ: evidence from 53 countries. Journal of Economic Psychology

World Bank Group. (2015). Mind, society and behavior(World Development Report). Washington, D.C.: World Bank.

World Health Organization - WHO. (2019). Fact sheet on depression. Washington, D.C.: World Bank. 